\title{
Preventive Exchange Blood Transfusion in Pregnant Women with Sickle Cell Disease: Maternal and Perinatal Prognosis in a Country with Limited Resources, Burkina Faso
}

\author{
Hyacinthe Zamané1,2*, Dantola Paul Kain1,2, Sibraogo Kiemtoré1,2, Abdoul Azize Diallo1, \\ Jean Baptiste Valéa1, Samba Diallo3 ${ }^{3}$, Fabienne Sanou4, Jean Lankoandé1,2 \\ ${ }^{1}$ Department of Obstetrics and Gynecology, Yalgado Ouedraogo Teaching Hospital in Ouagadougou, \\ Ouagadougou, Burkina Faso \\ ${ }^{2}$ Unity of Training and Research in Health Sciences (UFR/SDS), University of Ouagadougou, Ouagadougou, \\ Burkina Faso \\ ${ }^{3}$ National Center of Blood Transfusion, Ouagadougou, Burkina Faso \\ ${ }^{4}$ Department of Internal Medicine, Yalgado Ouedraogo Teaching Hospital in Ouagadougou, Ouagadougou, \\ Burkina Faso \\ Email: "zamanehyacinthe@gmail.com, "zamanehyacinthe@yahoo.fr
}

Received 21 April 2016; accepted 22 May 2016; published 25 May 2016

Copyright @ 2016 by authors and Scientific Research Publishing Inc.

This work is licensed under the Creative Commons Attribution International License (CC BY).

http://creativecommons.org/licenses/by/4.0/

(c) (i) Open Access

\section{Abstract}

Context: In pregnant women with sickle cell disease, the management with exchange transfusion could be useful in improving the prognosis of mother and child by reducing the level of hemoglobin $S$ less than $40 \%$. Objective: To analyze the maternal and perinatal outcome during the program of the exchange transfusion in pregnant women with sickle cell disease. Patients and Methods: We conducted a prospective study over a period of 18 months. Pregnant women with a major form of sickle cell disease were included. A manual blood exchange transfusion was performed monthly. We monitored the occurrence of maternal and perinatal morbidity during the follow-up. Results: A total of 42 pregnant women with sickle cell disease were monitored. The frequency of infectious episodes and vaso-occlusive crisis was significantly reduced, respectively from $47.6 \%$ and $83.3 \%$ before the beginning of the blood exchanges transfusion to $11.9 \%$ and $16.7 \%$ during blood exchanges transfusion program. All newborns were alive at birth with an Apgar score higher or equal to 7 at the $5^{\text {th }}$ minute. The rate of admission of the newborns at neonatal intensive care

${ }^{*}$ Corresponding author.

How to cite this paper: Zamané, H., Kain, D.P., Kiemtoré, S., Diallo, A.A., Valéa, J.B., Diallo, S., Sanou, F. and Lankoandé, J. (2016) Preventive Exchange Blood Transfusion in Pregnant Women with Sickle Cell Disease: Maternal and Perinatal Prognosis in a Country with Limited Resources, Burkina Faso. Open Journal of Obstetrics and Gynecology, 6, 373-378.

http://dx.doi.org/10.4236/ojog.2016.66048 
unit was $9.3 \%$. Maternal mortality was estimated at $7.1 \%$ and there was no early neonatal mortality. Conclusion: Prophylactic exchange transfusion reduces infections and the reoccurrence of vaso-occlusive crisis, which has an impact on perinatal prognosis.

\section{Keywords}

\section{Sickle Cell Disease, Exchange Transfusion, Maternal and Perinatal Prognosis}

\section{Background}

The pregnancy associated with sickle cell disease is a high-risk situation due to serious maternal and fetal complications which can occur [1]. The management with exchange transfusion though not yet a consensus in all its aspects [1] [2], could be useful in improving the prognosis of mother and child [3]-[5]. The objective of the exchange transfusion is to obtain at the time of birth, a level of hemoglobin S less than $40 \%$ and a fraction A1 at least 30\% without increasing the hemoglobin levels above $10-11 \mathrm{~g} / \mathrm{dl}$ [4]. This new therapy is still in its beginning in the African context where transfusion practice faces several challenges [6].

We report our experience of this type of management at the Yalgago Ouédraogo Teaching Hospital in Burkina Faso through an analysis of maternal and perinatal outcome in pregnant women with major sickle cell disease who benefited from the exchange transfusion.

\section{Patients and Methods}

A prospective descriptive and analytical study was performed over a period of 18 months, from February 2012 to June 2013. The study population consisted of pregnant women with sickle cell disease confirmed through hemoglobin electrophoresis including the SS, SC and S beta thalassemia genotypes. Having a hemoglobin level of at least $8 \mathrm{~g} / \mathrm{dl}$ was a prerequisite for the inclusion of patients in the exchange transfusion protocol [7]. Patients with a lower level of hemoglobin have rather benefited from a simple blood transfusion. The inclusion was done from 22 weeks of gestation for the SS patients and $\mathrm{S} / \beta+$ thalassemia and 32 weeks for heterozygous patients SC and those $S / \beta+$ thalassemia. However, it was done earlier depending on the severity of the clinical picture such as repetitive and severe crises. The exchange transfusion was performed manually in collaboration with the National Blood Transfusion Centre. A periodicity of 3 to 4 weeks was defined. The sessions were performed in a day care hospital setting, with a pre and post procedure blood check up within the 48 hours before and after exchange transfusion. The amount of bleeding was $10-15 \mathrm{ml} / \mathrm{kg}$ and the calculation was adjusted according to the hemoglobin level. The compensation was through a transfusion of packed red cells phenotyped (Rh: 1, 2, 3, 4, 5 and Kel: 1, 2) and cross matched. A monthly prenatal follow up and two monthly in the last months of pregnancy was performed until delivery. Episodes of maternal morbidity which occurred after the inclusion of patients in the protocol, the terms of delivery and the fetal and neonatal parameters were recorded. Informed consent was obtained from patients and the blood was freely provided. We have kept anonymous and confidential patient's information and the collected data. However we could not submit to the ethics committee for approval. To compare the outcome before and after the exchange transfusion, we used the Mac Nemar statistical test. The outliers' values were ignored in the analysis.

\section{Results}

\subsection{Characteristics of the Study Population}

In total 42 pregnant with sickle cell disease had benefited from the exchange transfusion. The mean age was 27.8 with a standard deviation of 4.8 years [20 - 38 years].

The average parity was $1.3 \pm 1.1$. A history of caesarian was found at 12 patient's (28.6\%). The number of alive children varied from 0 to 4 with an average of 0.5 . The average of the gestational age in the first session of transfusional exchange was 31, 22 and 24 weeks respectively for the forms SC, the SS and S/beta thalassemia. 
Twenty six patients (61.9\%) were not before followed in hematology. The data about the type of sickle cell disease and the chronic complications are summarized in Table 1.

\subsection{Morbidity before Exchange Transfusion}

Before the exchange transfusion 20 pregnant women (47.6\%) had at least one episode of infection due to malaria, lung infections and digestive salmonellosis and 35 (83.3\%) had at least one episode of vaso occlusive crisis.

\subsection{Data on Exchange Transfusion Sessions}

The mean gestational age at inclusion was 29.3 weeks [20 - 37] for homozygous SS and S/beta thalassemia and 32.7 weeks [26 - 40] for heterozygous SC patients. The median number of exchange transfusion was 01 [1 - 3] sessions with a mean interval between sessions of 04 weeks.

\subsection{Morbidity after Exchange Transfusion}

Incidents which occurred during blood transfusion are summarized in Table 2.

Infectious and vaso-occlusive crises constituted the majority of maternal morbidity recorded during the follow-up (Table 3).

\begin{tabular}{ll}
\hline Table 1. Types of sickle cell disease and patient’s histories $(\mathrm{n}=42)$. \\
\hline Past medical history & Number \\
\hline Types of major sickle cell disease & 36 \\
SC & 3 \\
SS & 3 \\
S/beta thalassémia & \\
Chronic complications of sickle cell & 12 \\
Proliferative retinopathy & 3 \\
Necrosis of the femoral head & 3 \\
Cholelithiasis & 2 \\
Osteomyelitis & 1 \\
\hline Glomerulonephritis & \\
\hline
\end{tabular}

Table 2. Incidents and accidents occurred during the exchange transfusion $(n=42)$.

\begin{tabular}{lcc}
\hline Incidents/accidents & Number & Percentage (\%) \\
\hline Difficult venous cannulation & 8 & 19.1 \\
Dyspnea & 2 & 4.8 \\
Vomiting & 1 & 2.4 \\
Dizziness & 1 & 2.4 \\
Hematoma at the injection site & 1 & 2.4 \\
Vaso-occlusive crisis & 1 & 2.4 \\
Non hemolytic fever & 1 & 2.4 \\
\hline
\end{tabular}


Table 3. Maternal morbid episodes occurring during the follow-up after the inclusion of the patients $(\mathrm{n}=42)$.

\begin{tabular}{ccccc}
\hline Morbid episod & Antenatal & Per partum & Post-partum & Total \\
\hline Infections $^{*}$ & 3 & 0 & 2 & $5(11.9)$ \\
Vaso occlusive crisis & 3 & 0 & 4 & $7(16.7)$ \\
Bleeding & 0 & 1 & 2 & $3(7.1)$ \\
Severe anemia & 0 & 0 & 1 & $1(2.4)$ \\
\hline
\end{tabular}

*infections = Malaria, salmonellosis, urinary tract infection, community acquired pneumonia.

However, we noted a significant reduction in these two types of morbidity, compared to the period before the exchange transfusion ( $\mathrm{p}<0.001$, Mac Nemar test). Three (7.1\%) maternal deaths including 01 antenatal and 02 in the postpartum were recorded. Severe malaria, septicemia and a likely pulmonary embolism were the causes of these deaths.

\subsection{Perinatal Outcome}

Caesarian-section was performed in 28 cases (68.3\%) of which 19 (46.3\%) in emergency. Two (02) preterm births were recorded. All the 42 infants with a 2 ser twins were all alive at birth. Apgar score in the $5^{\text {th }}$ minute was greater than or equal to 7 in all newborns. Birth weight ranged from 2000 to $3600 \mathrm{~kg}$ with an average weight of 2666.7 g. Five infants (11.6\%) including 02 preterm infants had a birth weight less than 2500 g. Four (9.30\%) newborns were admitted to neonatal intensive care unit 02 among them for infection and the two others for prematurity. The outcome was favorable for all newborns. No cases of neonatal death were recorded.

\section{Discussion}

Financial difficulties and constraints of laboratory have delayed the realization of the preliminary assessment in some patients what, with the delay in the consultation disrupted the respect for the desired rhythm of the sessions of transfusional exchange. It is to be taken into account in the analysis of the efficiency of the exchange. So the inclusion in different dates and gestational ages for patients of the same status could cause biases.

The heterozygous form SC was the most common reflecting the general situation of the distribution of hemoglobinopathies in Burkina Faso [8]. Also, hemolysis is more pronounced in sickle cell SS and these patients usually have a lower base level of hemoglobin which did not allow their inclusion in the study in accordance with the criteria of hemoglobin threshold which was set at $8 \mathrm{~g} / \mathrm{dl}$.

Chronic complications were dominated by proliferative retinopathy witch, if untreated before delivery, required a cesarean section for stage at or above III.

We used the manual exchange transfusion technique. Machine exchanges are faster and respect the isovolemia and more comfortable for patients. It control better the post-transfusion hematocrit, it does not induce deficiencies of coagulation factors in the hours following the exchange, nor a long-term iron overload. Its disadvantages are the high cost of the machines and their less availability [4]. The manual exchange, despite its drawbacks in opposition to automated, remains the technique of choice in the context of developing countries because of limited access to the red cell exchange by apheresis. A rate of exchange with at least 02 concentrated red cells every 3 to 4 weeks for manual exchange is necessary for the intended transfusion performance [3]. In our series, the late use of prenatal care, financial difficulties in paying the para clinical assessment pre and post transfusion and non-permanent availability of packed red blood cells are all factors that contributed to the late and irregular practice exchange sessions transfusion.

The incidents during transfusion processes were dominated by the difficulties of venous access due to progressive damage of the veins due to iterative punctures. The literature is rather contradictory regarding the effectiveness of exchange transfusion on maternal and fetal morbidity. Some authors found that routine transfusion does not improve obstetric outcomes [9] [10]. They do advocate this practice if there are particular medical history or in certain clinical settings. Further work in the opposite seems to show a beneficial effect of the iterative transfusion [5] [11]-[14]. In our series, the number of infectious episodes and vaso-occlusive crisis was significantly reduced after the exchange transfusion. All infants were alive at birth and perinatal morbidity were lesser, with a prematurity rate of $4.8 \%$, a proportion of low birth weight of $11.6 \%$ and an admission rate of $9.3 \%$ in 
neonatal intensive care unit. It is recognized that infections during pregnancy are a risk factor for preterm birth, low birth weight, fetal death in utero and neonatal morbidity. In addition, the vaso-occlusive crises are also repeated threat to fetal wellbeing. These crises could be maintained by repeated infectious episodes which are favored by the sickle cell disease. Also, it is important to remember that the risk of hemolysis with sudden massive deglobulinisation may be increased by the potential multiple forms of infection. Minimizing infections and reducing the frequency of crises during pregnancy probably contribute to improving the outcomes for both mother and child.

\section{Conclusion}

The blood is an important resource for the improvement of maternal and perinatal outcome in the context of sickle cell disease. At present, the practice of prophylactic exchange transfusion is still subject to controversy and is organized in different contexts. The significant reduction of infectious episodes and the frequency of vaso-occlusive crises advocate for this practice in the African context. However, other studies to compare the contribution of systematic exchange transfusion to the targeted transfusion are needed to better harmonize practices.

\section{Acknowledgements}

The National Blood Transfusion Centre for its collaboration.

\section{References}

[1] Berkane, N., Stefanescu, D., Haddad, B., Mathieu, E. and Uzan, S. (2003) Complications and Care of the Pregnancy in the Woman with Sickle Cell Disease. In: Girot, R., Bégué, P. and Galactéros, F., Eds., La drépanocytose, John Libbey Eurotext, Paris, 237-246.

[2] Okusanya, B.O. and Oladapo, O.T. (2013) Prophylactic versus Selective Blood Transfusion for Sickle Cell Disease in Pregnancy. Cochrane Database of Systematic Reviews, No. 12. Article No.: CD010378. http://dx.doi.org/10.1002/14651858.cd010378

[3] Habibi, A., Arletd, J.B., Stankovicf, K., Gellen-Dautremera, J., Ribeile, J.A., Bartoluccia, P., et al. (2015) French Recommendations of Care of the Sickle Cell Disease of the Adult: Updating 2015. La Revue de médecine interne, 36, 5S3-5S84.

[4] De Montalembert, M. (2007) Érythrocytaires Exchanges in the Patients with the Sickle Cell Disease. Hematology, 13, 243-249.

[5] Salque, C., Berrebi, A., Alie-Daram, S., Ayoubi, M. and Rigal-Huguet, F. (2001) Sickle Cell Disease and Pregnancy: About the Systematic Prophylatique Transfusion. Journal de Gynécologie Obstétrique et Biologie de la Reproduction, 30, 160-165.

[6] Dokekias, A.E. and Basseila, G.B. (2010) Results of the Partial Transfusional Exchanges at 42 Homozygous Drepanocytic Patients in the CHU of Brazzaville. Transfusion Clinique et Biologique, 17, 232-241. http://dx.doi.org/10.1016/j.tracli.2010.06.027

[7] De Montalembert, M. (2004) Blood Transfusion and Hemoglobinopathies Hematology. Hématologie, 6 , 470-478.

[8] Kafando, E., Sawadogo, M., Coton, F., Vertongen, F., Ferster, A. and Gulbis, B. (2005) Neonatal Screening for Sickle Cell Disorders in Ouagadougou, Burkina Faso: A Pilot Study. Journal of Medical Screening, 12, 112-114. http://dx.doi.org/10.1258/0969141054855300

[9] El-Shafei, A.M., Kaur Dhaliwal, J., Kaur Sandhu, A. and Rashid Al-Sharqi, M. (1995) Indications for Blood Transfusion in Pregnancy with Sickle Cell Disease. Australian and New Zealand Journal of Obstetrics and Gynaecology, 35, 405-408. http://dx.doi.org/10.1111/j.1479-828X.1995.tb02153.x

[10] Berkane, N., Nizard, J., Dreux, B., Uzan, S. and Girot, R. (1999) Sickle Cell Disease and Pregnancy. Complications and Taken Care. Pathologie Biologie, 47, 46-54.

[11] Bruce, I. and Sharon, E. (1994) Transfusion Therapy in Congenital Hemolytic Anemias. Transfusion Medicine, 1, 1053-1086.

[12] Morrison, J.C., Morrison, F.S., Floyd, R.C., Roberts, W.E., Hess, L.W. and Wiser, W.L. (1991) Use of Continuous Flow Erythrocytapheresis in Pregnant Patients with Sickle Cell Disease. Journal of Clinical Apheresis, 6, 224-229. http://dx.doi.org/10.1002/jca.2920060411

[13] Howard, R.J., Tuck, S.M. and Pearson, T.C. (1995) Pregnancy in Sickle Cell Disease in the UK: Results of a Multicenter Survey of the Effect of Prophylactic Blood Transfusion on Maternal and Fetal Outcome. British Journal of Ob- 
stetrics and Gynaecology, 102, 947-951. http://dx.doi.org/10.1111/j.1471-0528.1995.tb10900.x

[14] Driss, F., Tertian, G., Becquemont, L., Haddad, B., Cynober, T., Raphael, M., et al. (2007) Coverage of the Pregnancies at Risk in the Women with Sickle Cell Disease: Interest of a Preventive Strategy by Transfusions of Red Blood Cells or the Automated Exchanges of Erythrocytes. Transfusion Clinique et Biologique, 14, 386-392.

http://dx.doi.org/10.1016/j.tracli.2007.10.002 